\title{
Impacts of a farmers' market incentive programme on fruit and vegetable access, purchase and consumption
}

\author{
Lauren EW Olsho ${ }^{1, *}$, Gayle Holmes Payne ${ }^{2}$, Deborah Klein Walker ${ }^{1}$, Sabrina Baronberg ${ }^{3}$, \\ Jan Jernigan ${ }^{2}$ and Alyson Abrami ${ }^{3}$ \\ 'US Health Division, Abt Associates Inc., 55 Wheeler Street, Cambridge, MA 02138, USA: ${ }^{2}$ Division of Nutrition, \\ Physical Activity and Obesity, Centers for Disease Control and Prevention, Atlanta, GA, USA: ${ }^{3}$ Physical Activity and \\ Nutrition Program, NYC Department of Health and Mental Hygiene, New York, NY, USA
}

Submitted 17 October 2014: Final revision received 10 February 2015: Accepted 6 March 2015: First published online 29 April 2015

\begin{abstract}
Objective: The present study examines the impact of Health Bucks, a farmers' market incentive programme, on awareness of and access to farmers' markets, and fruit and vegetable purchase and consumption in low-income New York City neighbourhoods.

Design: The evaluation used two primary data collection methods: (i) an on-site point-of-purchase survey of farmers' market shoppers; and (ii) a random-digit-dial telephone survey of residents in neighbourhoods where the programme operates. Additionally, we conducted a quasi-experimental analysis examining differential time trends in consumption before and after programme introduction using secondary Community Health Survey (CHS) data.

Setting: New York City farmers' markets and communities.

Subjects: Farmers' market shoppers (n 2287) completing point-of-purchase surveys in a representative sample of New York City farmers' markets in 2010; residents ( $n$ 1025) completing random-digit-dial telephone survey interviews in 2010; and respondents ( $n$ 35 606) completing CHS interviews in 2002, 2004, 2008 and 2009.

Results: Greater Health Bucks exposure was associated with: (i) greater awareness of farmers' markets; (ii) increased frequency and amount of farmers' market purchases; and (iii) greater likelihood of a self-reported year-over-year increase in fruit and vegetable consumption. However, our CHS analysis did not detect impacts on consumption.

Conclusions: While our study provides promising evidence that use of farmers' market incentives is associated with increased awareness and use of farmers' markets, additional research is needed to better understand impacts on fruit and vegetable consumption.
\end{abstract}

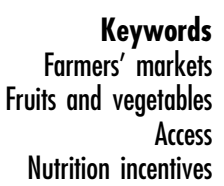

Obesity is a major public health concern. About one-third of US adults and $17 \%$ of children and adolescents are obese $^{(1,2)}$. Epidemiological studies indicate an association between increased fruit and vegetable consumption and reduced long-term obesity risk ${ }^{(3-9)}$ as well as reduced risk of heart disease and some cancers ${ }^{(10-15)}$. Nevertheless, relatively few Americans consume the recommended amounts of fruits and vegetables ${ }^{(16,17)}$. This is particularly true among low-income families and participants in federal nutrition assistance programmes like the Supplemental Nutrition Assistance Program (SNAP), populations least likely to meet recommended fruit and vegetable intake levels ${ }^{(18-20)}$.

In response to this growing public health crisis, some have advocated for targeted incentive or voucher programmes to encourage fruit and vegetable purchases $^{(21-23)}$. Such programmes make nutritious foods like fresh fruits and vegetables more affordable compared with less nutritious choices by affecting relative prices and enhancing overall purchasing power ${ }^{(21)}$. Farmers' markets in particular have been targeted by a number of incentive programmes as ideal sources for fresh fruits and vegetables within urban and low-income settings ${ }^{(24-26)}$.

The Health Bucks initiative, introduced in 2005, is a pioneering example of a farmers' market incentive programme. Funded by the New York City Department of Health and Mental Hygiene (DOHMH) and the Human Resources Administration, the Health Bucks programme's stated objectives are to: (i) increase consumption of fresh 
fruits and vegetables and thereby promote healthful diets; and (ii) expand access to locally grown produce at farmers' markets in low-income neighbourhoods. The programme operates through three District Public Health Offices (DPHO) established by DOHMH to reduce health inequalities in designated high-need New York City neighbourhoods (the South Bronx, North and Central Brooklyn, and East and Central Harlem; hereafter referred to as 'DPHO neighbourhoods').

'Health Bucks' are \$US 2 coupons redeemable for the purchase of fresh fruits and vegetables at participating farmers' markets; in 2011, sixty-five New York City farmers' markets accepted Health Bucks as a form of payment. The majority of Health Bucks are distributed directly to shoppers at farmers' markets in DPHO neighbourhoods as a SNAP incentive. Participating markets dispense one \$US 2 Health Buck coupon for every \$US 5 in benefits spent by SNAP participants using their electronic benefit transfer (EBT) cards, with no ceiling amount. In 2011, nearly 90000 Health Bucks were distributed as incentives to SNAP participants, with a $93 \%$ redemption rate. In addition, the DOHMH issues Health Bucks to communitybased organizations in DPHO neighbourhoods, which distribute the coupons directly to clients, often as an incentive to attend nutrition workshops or health and fitness programmes. Although there is no specific incomebased eligibility requirement for Health Bucks distributed via this mechanism, most participating community-based organizations served predominantly low-income clients. This distribution method promotes the programme to neighbourhood residents and encourages more first-time shoppers to purchase produce from their local farmers' markets. In 2011, more than 28000 Health Bucks were distributed through over 150 community-based organizations in DPHO neighbourhoods, with redemption rates topping $70 \%{ }^{(27)}$. Detailed information on Health Bucks history and implementation has been published elsewhere ${ }^{(28)}$.

Although incentive programmes at farmers' markets are growing as an approach to increase access to fresh fruits and vegetables, little is known about their effects on fruit and vegetable spending and intake ${ }^{(29-31)}$. The current paper presents results from a mixed-methods evaluation to assess the effectiveness of Health Bucks in increasing access to and awareness of farmers' markets, and increasing purchase and consumption of fruits and vegetables.

\section{Methods}

\section{Study design}

Our mixed-methods evaluation employed descriptive analysis of cross-sectional survey data collected directly from New York City farmers' market shoppers and residents of DPHO neighbourhoods and a quasi-experimental analysis of differential time trends in consumption before and after programme introduction using secondary Community Health Survey (CHS) data.

\section{Data sources}

The evaluation results reported here employed three data sources (two primary and one secondary). We provide a brief overview of data sources below; further detail is available by request from the corresponding author and survey instruments are provided as part of the online Health Bucks Evaluation Toolkit ${ }^{(32)}$. The study was conducted according to the guidelines laid down in the Declaration of Helsinki and all procedures involving human subjects were approved by the Abt Associates Institutional Review Board and the New York City DOHMH Institutional Review Board. Verbal informed consent was obtained from all subjects. Verbal consent was witnessed and formally recorded by interviewers.

\section{Farmers' market shopper survey}

Trained interviewers conducted intercept surveys on site with 2287 shoppers at eighty-six New York City farmers' markets during the 2010 farmers' market season (JulyNovember). Interview sites included all Health Bucks markets (1416 shoppers at forty-six markets in DPHO neighbourhoods) plus a random sample of nonparticipating markets (871 shoppers at forty markets outside DPHO neighbourhoods). Interviewers were stationed at high-traffic locations, approaching all eligible shoppers over age 18 years who had made market purchases that day, offering a round-trip MetroCard (\$US 4.50 value) as incentive for completion. Interviews were conducted in English and Spanish. The final sample reflects a completion rate of $72 \%$ of shoppers approached, excluding incompletes due to screen-outs, refusals and language barriers. We asked shoppers about market purchases that day, and access to and consumption of fruits and vegetables from farmers' markets and other sources. In Health Bucks markets only, we asked about Health Bucks knowledge and experiences. Supplemental Table 1 (see online supplementary material) provides demographic data on farmers' market shopper survey respondents.

\section{Neighbourbood resident survey}

Near the end of the 2010 farmers' market season, we conducted a random-digit-dial telephone survey of 1025 residents stratified by DPHO neighbourhood, with about a third of respondents in each of the three neighbourhoods. A zip exchange analysis was used to identify telephone exchanges in each neighbourhood; cell phone exchanges were not included. Eligible respondents were residents of DPHO-neighbourhood zip codes aged 18 years and above who were the primary food shopper for their household. Interviews were conducted in English and Spanish. The overall response rate was $39 \%$. The survey's objective was to obtain information on a representative sample of DPHO-neighbourhood households, to characterize overall 
programme knowledge and attitudes and provide a point of comparison for the shopper survey. Respondents reported on experiences with farmers' markets, access to and consumption of fruits and vegetables from farmers' markets and other sources, and Health Bucks knowledge and experiences. Supplemental Table 2 (see online supplementary material) provides demographic data on neighbourhood resident survey respondents.

\section{Community bealth survey}

The New York City Community Health Survey (CHS) is an annual cross-sectional telephone survey conducted for DOHMH by Abt SRBI Inc. Its objective is to provide representative data on the health of New Yorkers at the neighbourhood, borough and citywide level, including estimates on prevalence of chronic disease and behavioural risk factors ${ }^{(33)}$. Although many CHS questions are repeated annually, others are asked only on a one-time or periodic basis, to allow timely survey coverage of a wider breadth of topics and issues of emerging interest without undue respondent burden. Our analysis uses a consumption measure (total servings of fruits and vegetables eaten on the previous day) that was collected in four survey years: 2002 and 2004, prior to the 2005 implementation of Health Bucks, and 2008 and 2009, after the programme was well established. The overall response rate ranged from $29 \%$ to $36 \%$ across the four survey years. Across all four years, there were 35606 individual CHS observations.

\section{Analyses}

We synthesized available information from each data source in this mixed-methods evaluation on three outcome areas of interest (awareness and access, purchasing, and consumption) to provide a range of evidence on programme impacts. Our primary data collection activities allowed us to directly observe associations between Health Bucks exposure and outcomes, but because these data were collected at a single point in time, ability to draw causal inference is limited. The secondary CHS data are repeated over time both before and after Health Bucks implementation, providing a more robust basis for causal inference by allowing us to compare trends in DPHO and non-DPHO neighbourhoods after programme introduction. However, because we cannot directly observe respondent use of Health Bucks, residence in a DPHO neighbourhood is the nearest available CHS proxy for Health Bucks exposure. In this sense, our primary and secondary data analyses represent useful complements, together providing a more complete perspective on programme exposure and impacts.

\section{Cross-sectional survey analyses}

We used questions from the farmers' market shopper and neighbourhood resident surveys to construct measures of respondent exposure to Health Bucks. Neighbourhood residents were categorized by whether they had ever shopped at a farmers' market; farmers' market shoppers were categorized by whether the interview occurred at a market accepting Health Bucks or a non-participating market. Respondents were then further categorized by prior awareness of Health Bucks (ever heard of Health Bucks); any previous Health Bucks use (ever used Health Bucks to make purchases); and current Health Bucks use (use on the day of the interview for farmers' market shoppers or during the current farmers' market season for neighbourhood residents), with each subsequent subcategorization representing a higher level of programme exposure (see online supplementary material, Supplemental Fig. 1 and Supplemental Fig. 2). For each set of subgroups, we report $\chi^{2}$ tests for differences in categorical outcome measures and $t$ tests for differences in means for continuous outcome measures, along with $P$ values indicating statistically significant differences. Shopper survey analyses incorporate sampling weights to account for probability of market selection and neighbourhood survey analyses incorporate sampling weights to account for household selection probability. We separately report results for the respondent sub-sample who participated in SNAP, to enable comparisons by Health Bucks exposure level within a more homogeneous subpopulation. Regression adjustment for differences in demographic characteristics (age, sex and race/ethnicity) did not materially alter findings; we therefore report unadjusted means and percentages here for simplicity of interpretation.

\section{Difference-in-differences analysis of community bealth survey data}

Finally, we estimated programme impacts on trends in fruit and vegetable consumption using individual-level CHS data. The analysis proceeds on the following intuition. If Health Bucks increases fruit and vegetable consumption, we would expect a more favourable trend in DPHO neighbourhoods after programme introduction. However, simple pre-post comparisons within DPHO neighbourhoods could be confounded by broader citywide factors influencing consumption over the same time period. We thus use individuals residing in non-DPHO New York City neighbourhoods as an outside comparison group, since we would not expect Health Bucks to influence consumption trends in these areas. Any differences in trends after programme introduction in DPHO neighbourhoods as compared with non-DPHO neighbourhoods are interpreted as Health Bucks programme impacts. This approach is known in the evaluation literature as a difference-in-differences design.

Specifically, we used linear regression to estimate the difference in fruit and vegetable consumption trends in DPHO neighbourhoods after Health Bucks implementation. Formally, we have self-reported data on fruit and 
vegetable consumption, $y$, of individuals, $i$, in neighbourhoods, $g$, in time period, $t$ :

$$
y_{g, i, t}=\alpha+H_{g, t} \beta+M_{g} \mu+T_{t} \tau+X_{i, t} \gamma+W_{g, t} \delta+\varepsilon_{g, i, t},
$$

where $H$ is an indicator variable equal to 1 in DPHO neighbourhoods after Health Bucks introduction, and 0 otherwise; $M$ is an indicator variable equal to 1 in DPHO neighbourhoods in all years, and 0 otherwise; and $T$ is a series of indicator variables for survey year $(2004,2008$ or 2009 , with 2002 as the excluded year). $\beta$ is the key parameter of interest, representing programme impact as the difference in fruit and vegetable consumption in DPHO neighbourhoods after Health Bucks began, adjusted for time-invariant neighbourhood-level effects captured by $\mu$ and citywide trends by year captured by $\tau$. In some specifications we additionally include $X$, a vector of individual-level characteristics influencing consumption (sex, race/ethnicity, age group, employment, educational attainment); and $W$, a vector of time-varying neighbourhood-level characteristics (presence of food retail establishments from Census zip code business pattern data, proportion of neighbourhood residents below $200 \%$ of the poverty line). We account for correlation in standard error $\varepsilon$ across individuals residing in the same neighbourhood by clustering at the neighbourhood level ${ }^{(34)}$. Finally, we incorporate appropriate sampling weights and techniques to account for survey non-response and the complex CHS survey design, so results can be considered representative of New York City households with landline telephone service.

\section{Results}

\section{Awareness of and perceived access to farmers' markets}

Sixty-three per cent of neighbourhood residents, and $68 \%$ of SNAP participants in the neighbourhood resident survey, reported that there was a farmers' market in their neighbourhood. For both the full sample and the SNAP participant sub-sample, farmers' market awareness rose with Health Bucks exposure: those who had used Health Bucks during the current season were most likely to report that there was a farmers' market in their neighbourhood, followed by those who had ever used Health Bucks, those who had heard of Health Bucks (whether or not they had actually used them) and those who said they sometimes shopped at a farmers' market.

Neighbourhood resident survey respondents were also asked how long it would take to walk to the nearest source of fresh fruits and vegetables (under $5 \mathrm{~min}, 5-10 \mathrm{~min}$ or over $10 \mathrm{~min}$ ), to assess perceived geographic accessibility. There were no statistically significant differences in reported walking time by Health Bucks exposure.

\section{Purchasing patterns}

\section{Frequency of farmers' market shopping}

Figure 1 shows self-reported frequency of shopping at farmers' markets by DPHO neighbourhood residents and shoppers at Health Bucks markets, with responses stratified by programme exposure level. The $\chi^{2}$ tests indicated that greater Health Bucks exposure was significantly associated with more frequent farmers' market shopping for both groups $(P=0.001$ in both cases). In particular, among neighbourhood residents, $24 \%$ who had never heard of Health Bucks said they shopped at farmers' markets once per week or more, as compared with $32 \%$ who had heard of Health Bucks, $41 \%$ who had used Health Bucks and $49 \%$ who had used Health Bucks during 2010. At the other end of the scale, $35 \%$ of neighbourhood survey respondents who had never heard of Health Bucks said they never shopped at farmers' markets, as compared with $23 \%$ who had heard of Health Bucks, $8 \%$ who had used Health Bucks and $8 \%$ who had used Health Bucks this season. Greater programme exposure was similarly significantly associated with more frequent farmers' market visits for farmers' market shoppers, although the distribution of shopper responses was skewed towards a higher frequency than in the resident survey.

In both respondent groups, the majority directly credited Health Bucks for increasing frequency of farmers' market visits. Fifty-four per cent of Health Bucks users at markets accepting Health Bucks strongly agreed that 'I shop at farmers' markets more often because of Health Bucks' and another $18 \%$ somewhat agreed. Among neighbourhood residents, 39\% of Health Bucks users strongly agreed and another $16 \%$ somewhat agreed.

\section{Purchase amounts}

In addition to crediting Health Bucks for more frequent market visits, respondents reported that Health Bucks induced them to spend more at farmers' markets overall. Fifty-seven per cent of Health Bucks users surveyed on site strongly agreed that 'I buy more at farmers' markets because of Health Bucks' and another 15\% somewhat agreed. Among Health Bucks users residing in DPHO neighbourhoods, $18 \%$ strongly agreed and $37 \%$ somewhat agreed.

On site at farmers' markets, most Health Bucks users also agreed that 'I spend more in Food Stamps (aka SNAP or EBT benefits) at farmers' markets because of Health Bucks', with 39\% strongly agreeing and 18\% somewhat agreeing. For Health Bucks users in our neighbourhood resident survey, however, only $22 \%$ strongly agreed and $15 \%$ somewhat agreed.

\section{Purchase types}

Table 1 presents the percentage of farmers' market shoppers surveyed on site reporting purchases of fruits and vegetables at the market on the interview day, and the 
(a)

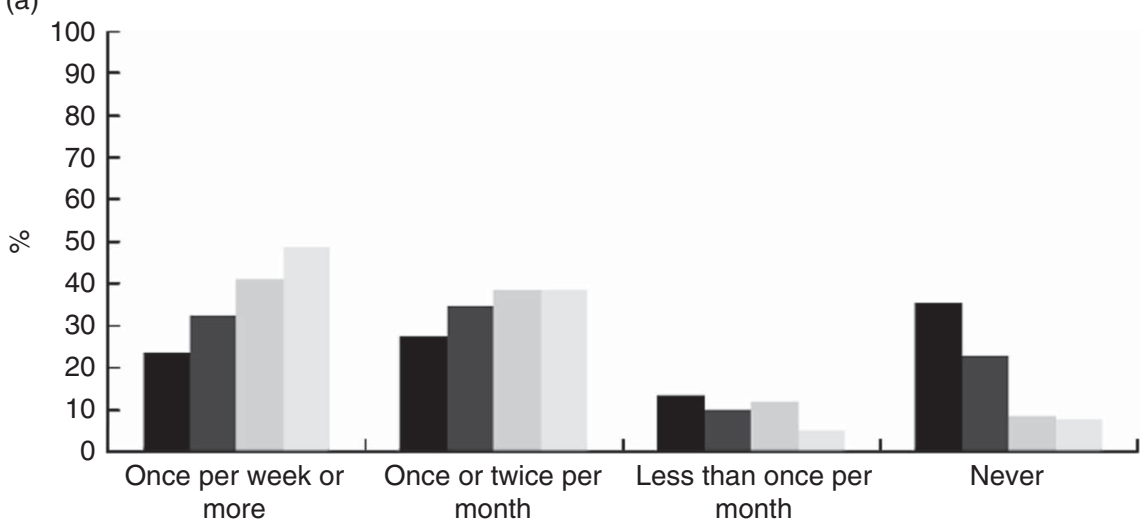

(b)

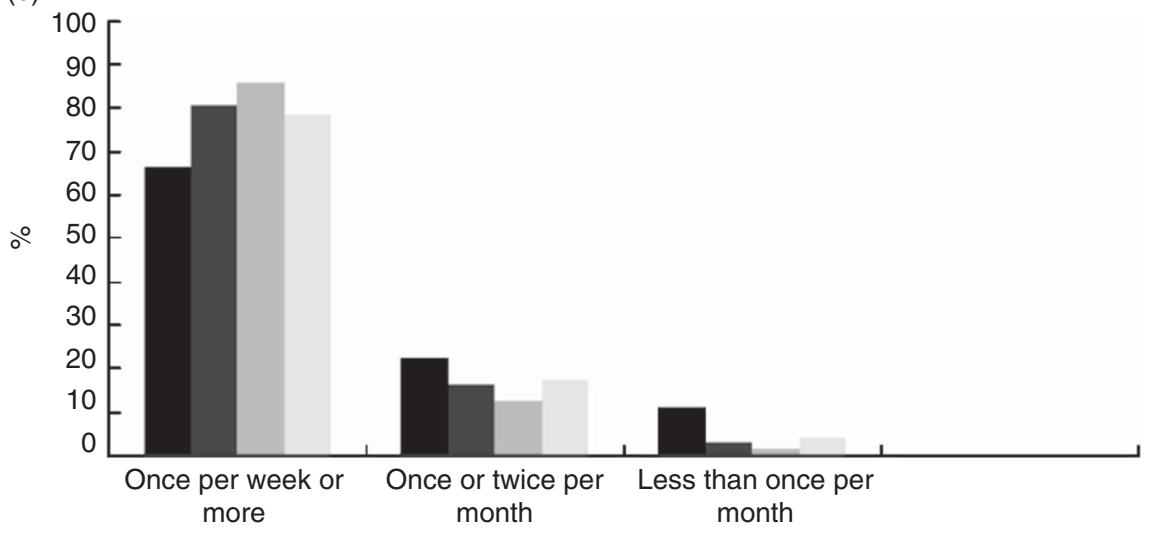

Fig. 1 Frequency of shopping at farmers' markets, by level of experience with Health Bucks ( $\square$, never heard of Health Bucks; $\square$, heard of Health Bucks; , ever used Health Bucks; , used Health Bucks in 2010 season (a)/used Health Buck that day (b)), among (a) DPHO neighbourhood residents† ( $n$ 997) and Health Bucks farmers' market shoppers $\ddagger$ ( $n$ 1416). †Neighbourhood resident survey analytic sample excludes twenty-eight 'don’t know' or 'refused' responses; łnote that since all farmers' market shopper surveys were conducted on site at the farmers' market, 'never shopped at a farmers' market' was not provided as a possible response category for this respondent group. All differences in frequencies across respondent subgroups by level of Health Bucks exposure were statistically significant $\left(P=0.001, x^{2}\right.$ test). (DPHO, District Public Health Office)

Table 1 Percentage of farmers' market shoppers reporting purchases of fruits and vegetables and other items at the market that day, all shoppers and SNAP participants, by Health Bucks exposure levels

\begin{tabular}{|c|c|c|c|c|}
\hline \multirow[b]{2}{*}{$\begin{array}{l}\text { Respondent group ( } n \text { for all respondents } / n \text { for SNAP } \\
\text { participants) }\end{array}$} & \multicolumn{2}{|c|}{ All respondents ( $n$ 2287) } & \multicolumn{2}{|c|}{ SNAP participants ( $n$ 635) } \\
\hline & $\begin{array}{l}\text { Fruits \& vegetables } \\
\qquad(\%)\end{array}$ & $\begin{array}{l}\text { Other items } † \\
(\%)\end{array}$ & $\begin{array}{l}\text { Fruits \& vegetables } \\
\qquad(\%)\end{array}$ & $\begin{array}{c}\text { Other items } † \\
(\%)\end{array}$ \\
\hline Health Bucks markets ( $n$ 1416/524) & $95 \cdot 4$ & $24 \cdot 3$ & $97 \cdot 3$ & $13 \cdot 5$ \\
\hline Others $(n 871 / 111)$ & $\underset{* *}{91.4}$ & $32 \cdot 5$ & $\underset{* \star}{91 \cdot 0}$ & $\begin{array}{c}19 \cdot 8 \\
(*)\end{array}$ \\
\hline Heard of Health Bucks ( $n$ 411/235) & $97 \cdot 1$ & $21 \cdot 7$ & $97 \cdot 0$ & $15 \cdot 3$ \\
\hline Never heard of Health Bucks ( $n$ 1005/289) & $\begin{array}{c}94 \cdot 7 \\
\left({ }^{*}\right)\end{array}$ & $25 \cdot 4$ & $97 \cdot 6$ & $12 \cdot 0$ \\
\hline Ever used Health Bucks ( $n$ 270/182) & $98 \cdot 1$ & $18 \cdot 1$ & 98.4 & $13 \cdot 7$ \\
\hline Never used Health Bucks ( $n$ 1146/342) & $\underset{*}{94 \cdot 8}$ & $\underset{* *}{25 \cdot 7}$ & $96 \cdot 8$ & $13 \cdot 5$ \\
\hline Used Health Bucks today ( $n$ 122/84) & $99 \cdot 2$ & $13 \cdot 1$ & $100 \cdot 0$ & 8.3 \\
\hline Did not use Health Bucks today ( $n$ 1294/440) & $\stackrel{95 \cdot 1}{*}$ & $\underset{* *}{25 \cdot 3}$ & $96 \cdot 8$ & 14.5 \\
\hline
\end{tabular}

SNAP, Supplemental Nutrition Assistance Program.

Significant difference across respondent subgroups by level of Health Bucks exposure $\left(X^{2}\right.$ test): $\left({ }^{\star}\right) P<0 \cdot 10,{ }^{\star} P<0 \cdot 05,{ }^{\star *} P<0 \cdot 01$.

†Includes jams/juices, bread, cheese, meats/fish, baked goods, and other unspecified items. Respondents could report purchases of both fruits and vegetables and other items. 
percentage reporting purchases of other items, broken down by SNAP participation and programme exposure.

The likelihood of a fruit or vegetable purchase at the market that day (including both purchases with Health Bucks and purchases with other forms of payment) increased with Health Bucks exposure. Among all respondents, $99 \%$ of those who had used Health Bucks that day had purchased fruits or vegetables,* as compared with only $95 \%$ of shoppers who had not used Health Bucks that day $(P=0.04)$. At successively lower degrees of Health Bucks exposure, $98 \%$ of respondents who had ever used Health Bucks reported a fruit or vegetable purchase that day (compared with $95 \%$ of those who never used Health Bucks, $P=0.02$ ), $97 \%$ who had heard of Health Bucks reported a fruit or vegetable purchase that day (compared with $95 \%$ of those who had never heard of Health Bucks, $P=0.06$ ) and $95 \%$ of shoppers at Health Bucks markets reported a fruit or vegetable purchase that day (compared with $91 \%$ of shoppers at non-Health Bucks markets $P<0.001)$. Patterns were similar among the SNAP participant sub-sample. For purchases of other items (e.g. breads, jams/juices, cheese, etc.), however, this trend was reversed, with likelihood of purchase decreasing with programme exposure.

\section{Fruit and vegetable consumption}

Table 2 shows results from the neighbourhood resident and shopper surveys on the mean servings of fruits and vegetables consumed the prior day and the percentage who reported eating more fruits and vegetables now than one year ago.

Among neighbourhood residents, farmers' market shoppers reported consuming a higher number of fruit and vegetable servings on the previous day, both in the full sample and in the SNAP sub-sample. However, there was no consistent pattern in consumption associated with neighbourhood resident knowledge or use of Health Bucks. Similarly, we did not observe higher levels of fruit and vegetable consumption by Health Bucks awareness and use among farmers' market shoppers surveyed on-site. Furthermore, shoppers at Health Bucks markets reported fewer servings consumed than shoppers at nonHealth Bucks markets.

When asked to assess fruit and vegetable consumption today $v$. consumption one year ago, however, Health Bucks users in both cross-sectional surveys were more likely to report increased consumption. Furthermore, 64\% of DPHO neighbourhood residents who had heard of Health Bucks and $81 \%$ of shoppers at Health Bucks markets somewhat or strongly agreed that Health Bucks helped them to eat more fruits and vegetables.

* Note that Health Bucks can only be used to purchase fruits and vegetables, implying that $100 \%$ of those who used Health Bucks at the market that day should have also reported purchasing fruits and vegetables. We suspect misreporting by the single respondent (one of 122 in all) who reported that $\mathrm{s} /$ he did not purchase fruits or vegetables that day.

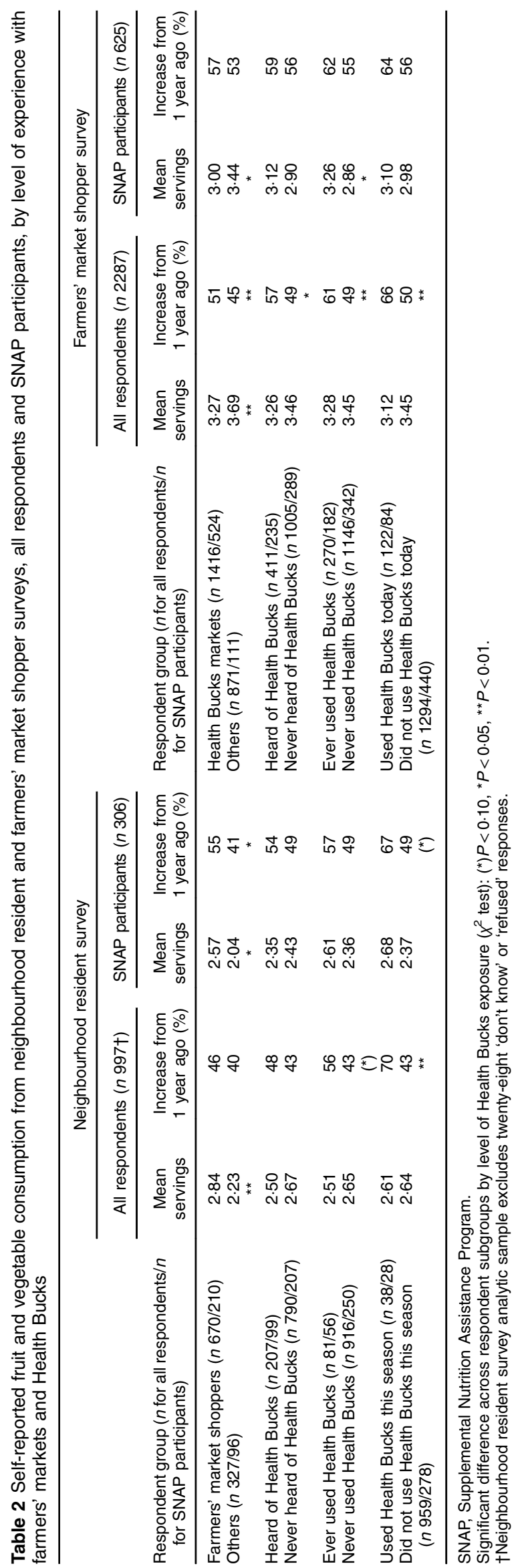


Table 3 Difference-in-differences estimates of impacts on self-reported servings of fruits and vegetables on previous day, Community Health Survey respondents, 2002-2009

\begin{tabular}{|c|c|c|c|c|c|c|c|c|}
\hline & \multicolumn{8}{|c|}{ Specification $\dagger$} \\
\hline & 1 & SE & 2 & SE & 3 & SE & 4 & SE \\
\hline $\begin{array}{l}\beta \text { : estimated impact (regression-adjusted difference in fruit \& } \\
\text { vegetable servings in DPHO neighbourhoods after Health } \\
\text { Bucks implementation) }\end{array}$ & 0.013 & 0.013 & -0.005 & 0.014 & 0.004 & 0.014 & 0.002 & 0.014 \\
\hline$\mu:$ average effect of DPHO neighbourhood residence & $-0 \cdot 141^{\star * *}$ & 0.010 & $-0.045^{\star \star *}$ & 0.013 & $-0.029^{* \star *}$ & 0.010 & -0.018 & 0013 \\
\hline$\tau_{2004}:$ year effect, 2004 v. 2002 & 0.006 & 0.007 & $0.023^{\star \star *}$ & 0.008 & 0.007 & 0.007 & 0.009 & 0.008 \\
\hline$\tau_{2008:}$ year effect, 2008 v. 2002 & 0.012 & 0.008 & $0.039^{\star * *}$ & 0.008 & 0.003 & 0.007 & 0.010 & 0.008 \\
\hline$\tau_{2009}$ : year effect, 2009 v. 2002 & $0.033^{\star \star \star}$ & 0.008 & $0.060^{\star \star *}$ & 0.008 & $0.027^{\star \star \star}$ & 0.008 & $0.031^{\star * *}$ & 0.008 \\
\hline $\begin{array}{l}\text { Regression adjusts for individual characteristics: sex, race/ } \\
\text { ethnicity, age group, employment, educational attainment }(X)\end{array}$ & $\mathrm{N}$ & & $\mathrm{N}$ & & $Y$ & & $\mathrm{Y}$ & \\
\hline $\begin{array}{l}\text { Regression adjusts for time-varying neighbourhood } \\
\text { characteristics: presence of food retail establishments from } \\
\text { Census zip code business pattern data, proportion of } \\
\text { neighbourhood residents below } 200 \% \text { of the poverty line }(\mathrm{W})\end{array}$ & $\mathrm{N}$ & & Y & & $\mathrm{N}$ & & $Y$ & \\
\hline $\begin{array}{l}\text { Number of respondents } \\
R^{2}\end{array}$ & $\begin{array}{r}3560 \\
0.011\end{array}$ & & $\begin{array}{r}35606 \\
0.025\end{array}$ & & $\begin{array}{r}3458 \\
0.065\end{array}$ & & $\begin{array}{r}3458 \\
0.072\end{array}$ & \\
\hline
\end{tabular}

DPHO, District Public Health Office; N, no; Y, yes.

${ }^{*}$ Significant at $5 \% ;{ }^{* *}$ significant at $1 \%$; ${ }^{\star * *}$ significant at $1 \%$

†Specifications 1-4 differ by inclusion/exclusion of individual characteristics $(X)$ and time-varying neighbourhood characteristics $(W$ ).

In addition to correlational findings from our crosssectional surveys, for fruit and vegetable consumption we report difference-in-differences findings based on CHS data. Table 3 shows estimated regression results for models including and excluding individual- and neighbourhood-level characteristics. We found no evidence of differentially larger increases in self-reported fruit and vegetable consumption in DPHO neighbourhoods as compared with other neighbourhoods. In particular, the positive and significant parameter $\tau_{2009}$ shows that average fruit and vegetable consumption increased in all New York City neighbourhoods from 2002 to 2009. However, the impact parameter $\beta$ was not statistically significant in any specification, indicating that this increase was not differentially larger in DPHO neighbourhoods after Health Bucks implementation.

\section{Discussion}

The present study's goal was to evaluate the effectiveness of Health Bucks in improving access to and awareness of farmers' markets and in increasing purchase and consumption of fruits and vegetables among targeted lowincome populations.

While we found that greater Health Bucks exposure was associated with greater awareness of farmers' markets, we did not find statistically significant increases in perceived access to farmers' markets, as measured by reported walking distance to the nearest market. Note, however, that just over $50 \%$ of farmers' market shoppers we interviewed reported that the market where they were surveyed was over $10 \mathrm{~min}$ away. It may be that our simple walking time metric may not capture all important dimensions of 'access' in this context, as shoppers seem to be willing to travel longer distances to reach farmers' markets if necessary. Prior research has indicated that incentive programmes like Health Bucks can improve access to farmers' markets by removing financial and logistical burdens for markets and participants in food assistance programmes ${ }^{(35-37)}$.

Increased Health Bucks exposure was also found to be associated with increased self-reported frequency and amounts of farmers' market purchases. Additionally, farmers' market shoppers with greater exposure to Health Bucks reported a greater likelihood of having purchased fruits and vegetables at the market that day. While our analysis focused on effects of the programme on individual spending and shopping patterns, this finding is consistent with related work examining effects on spending from the perspective of the farmers' market. For example, farmers' market managers and vendors agreed that they made more money at the market and sold more fruits and vegetables due to Health Bucks ${ }^{(28)}$, and farmers' markets accepting Health Bucks coupons averaged higher daily SNAP sales than markets not accepting the coupons ${ }^{(38)}$. Freedman and colleagues similarly found increased use of all forms of food assistance at the farmers' market associated with introduction of an incentive programme ${ }^{(39)}$.

Finally, we found mixed evidence regarding the effect of Health Bucks on consumption of fruits and vegetables. Greater Health Bucks exposure was associated with a greater likelihood of a self-reported year-over-year increase in fruit and vegetable consumption among farmers' market shoppers as well as residents of DPHO neighbourhoods. This is consistent with findings from an evaluation of Philly Food Bucks, a farmers' market incentive programme for SNAP participants in low-income Philadelphia neighbourhoods, which similarly found selfreported increases in fruit and vegetable consumption 
among Philly Food Bucks users ${ }^{(40)}$. In addition, DPHO neighbourhood residents who shopped at farmers' markets reported higher current levels of fruit and vegetable consumption, consistent with prior research indicating an association between fruit and vegetable consumption and farmers' market use among low-income populations ${ }^{(37,41)}$.

However, we did not find evidence of an association between Health Bucks awareness or use and self-reported fruit and vegetable consumption. Furthermore, prior-day fruit and vegetable servings were lower among shoppers at Health Bucks markets than in other farmers' markets, likely reflecting the fact that Health Bucks markets were intentionally located in underserved DPHO areas with lower levels of fruit and vegetable consumption overall. These findings suggest differences in fruit and vegetable consumption by use of farmers' markets, but not necessarily by Health Bucks exposure.

In addition, we did not detect an impact of Health Bucks on fruit and vegetable consumption levels in DPHO neighbourhoods in our CHS difference-in-differences analysis. One possible explanation is that the scale of the programme may be insufficient to generate impacts detectable at the community level using available data. Only $21 \%$ of respondents in DPHO neighbourhoods had heard of the Health Bucks programme, while $8 \%$ reported that they had actually used Health Bucks and just $4 \%$ that they had used Health Bucks that season. We may have detected a statistically significant impact either with a larger analytic sample size, greater programme size or a more finely grained measure of exposure to Health Bucks than our simple DPHO residence measure.

\section{Strengths and limitations of the study}

Our mixed-methods evaluation design includes multiple, complementary components, each with its own unique strengths and limitations.

The DPHO neighbourhood resident and farmers' market shopper surveys incorporate detailed measures of respondents' farmers' market and Health Bucks use, along with a wide range of outcome measures of interest, including awareness of and perceived access to farmers' markets, as well as self-reported fruit and vegetable spending and consumption measures. The representative sample of DPHO neighbourhood residents offers important contextual evidence on the programme's target population and reach to inform other aspects of the study. The survey of farmers' market shoppers in Health Bucks and non-Health Bucks markets, which is, to our knowledge, the largest field survey of farmers' market shoppers to have been conducted, similarly provides information on outcomes among those most likely to actually participate in the programme, along with other farmers' market shoppers as a point of comparison to allow assessment of similarities and differences among these groups. However, our ability to draw causal inference from these two surveys is limited, because data were collected during a single market season after programme implementation. Additionally, because the shopper survey was conducted on site at farmers' markets, these data cannot be used to answer questions about the broader community; conversely, because the sample for the neighbourhood resident survey was randomly selected from communities targeted by Health Bucks, these results include responses from individuals who may not be familiar with farmers' markets or with Health Bucks. As well, like all selfreported data, survey responses may be subject to social desirability bias, in which respondent reports are influenced by norms about the most socially acceptable response to survey questions. Finally, the relatively low response rate for the neighbourhood resident survey may raise concerns about non-response bias, and the exclusion of cell phone-only households may additionally bias the results.

Our difference-in-differences analysis of CHS data has strengths that directly complement limitations of our two primary data collection efforts. In particular, as noted in the introduction, the repeated cross-section design provides a basis for causal inference, in contrast to the single-point-in-time structure of the other two surveys. However, the CHS secondary data analyses are also limited in several ways. First, the CHS measure of fruit and vegetable consumption is the same measure we used in our cross-sectional surveys, offering a valid point of comparison, but the CHS did not include questions about Health Bucks or other outcomes of interest, like farmers' market access and purchasing. Second, the CHS sample does not include households with no telephone service or cell phone-only households, so weighted results are representative only of New York City households with landline telephone service; since cell phone usage increased over this time period, it is possible that excluding cell phone-only households may have distorted observed time trends. Third, we cannot rule out the possibility of non-response bias due to differences in unobservable characteristics among CHS respondents or the impact of contextual and environmental policy differences related to food programmes or neighbourhood characteristics that we did not measure. For this reason, it may be difficult to statistically isolate effects of Health Bucks in the CHS analysis.

\section{Conclusion}

Public health advocates and policy makers are increasingly promoting farmers' markets as a viable source of fresh fruits and vegetables in low-income, urban settings. As part of these broader promotional efforts, farmers' market incentive programmes have sharply proliferated in communities across the USA in recent years ${ }^{(42)}$. Health Bucks is one of the earliest and most mature of these 
initiatives and through its successful implementation has demonstrated the feasibility and sustainability of such strategies, with steadily increasing numbers of participating farmers' markets and participants over time ${ }^{(28)}$. With the recent announcement of the US Department of Agriculture's Food Insecurity Nutrition Incentive Grant Program ${ }^{(43)}$, funding and support for similar programmes will expand considerably in the near future.

And yet, while nutrition incentives have been demonstrated as an effective strategy for improving fruit and vegetable consumption among SNAP participants in general $^{(44,45)}$, to date there is still relatively little rigorous evidence on the effectiveness of these programmes in the farmers' market context ${ }^{(38-40)}$. While our study provides promising evidence that use of farmers' market incentives is associated with improved short-term outcomes such as awareness and use of farmers' markets, additional research is needed to better understand impacts on outcomes such as fruit and vegetable consumption, and, ultimately, overall nutritional and health status.

\section{Acknowledgements}

Acknowledgements: The authors wish to acknowledge the valuable contributions of Yvonne Abel, Cheryl Austin, Cristina Booker, Diane Eggert, Diane Gibson, Jacey Greece, Kasey Holloway, Sonia Kim, Erin Lee, Jessica Levin, Bob Lewis, Tara Merry, Cathy Nonas, Leah StaubDeLong, Alexis Stevens, Raegan Tuff, Andy Weiss and Holly Wethington to this evaluation study. They also thank the Abt Associates Journal Authors Support Group for valuable comments on the manuscript draft. Financial support: This evaluation study was funded by the Centers for Disease Control and Prevention (CDC) (under contract \#200-2008-27954, TO \#2009-LB-14). The CDC had no role in the design, analysis or writing of this article. The findings and conclusions in this report are those of the authors and do not necessarily represent the official position of the CDC. Conflicts of interest: None. Authorship: L.E.W.O. led development of the study design and led analysis, data collection and manuscript development. G.H.P. contributed to interpretation and synthesis of results, and manuscript development and revision. D.K.W. served as Principal Investigator for the study, with oversight for all design, data collection, analysis and writing tasks. S.B. contributed to the study design and interpretation of results, as well as manuscript revisions. J.J. contributed to interpretation and synthesis of results, and manuscript development and revision. A.A. contributed to the study design and interpretation of results, as well as manuscript revisions. Ethics of human subject participation: This evaluation study was reviewed and approved by the Abt Associates Institutional Review Board and the New York City DOHMH Institutional Review Board.

\section{Supplementary material}

To view supplementary material for this article, please visit http://dx.doi.org/10.1017/S1368980015001056

\section{References}

1. Flegal KM, Caroll MD, Ogden CL et al. (2010) Prevalence and trends in obesity among US adults, 1999-2008. JAMA 303, 235-241.

2. Ogden CL, Carroll MD, Curtin LR et al. (2010) Prevalence of high body mass index in US children and adolescents, 2007-2008. JAMA 303, 242-249.

3. He K, Hu FB, Colditz GA et al. (2004) Changes in intake of fruits and vegetables in relation to risk of obesity and weight gain among middle-aged women. Int J Obes Relat Metab Disord 28, 1569-1574.

4. Koh-Banerjee P, Chu NF \& Speigelman D (2003) Prospective study of the association of changes in dietary intake, physical activity, alcohol consumption, and smoking with 9-year gain in waist circumference among 16,587 US men. Am J Clin Nutr 78, 719-727.

5. Newby PK, Muller D, Hallfrisch J et al. (2003) Dietary patterns and changes in body mass index and waist circumference in adults. Am J Clin Nutr 77, 1417-1425.

6. Quatromoni PA, Copenhafer DL, D'Agostino RB et al. (2002) Dietary patterns predict the development of overweight in women: the Framingham Nutrition Studies. $J$ Am Diet Assoc 102, 1239-1246.

7. Fuglestad PT, Jeffery RW \& Sherwood NE (2012) Lifestyle patterns associated with diet, physical activity, body mass index and amount of recent weight loss in a sample of successful weight losers. Int J Behav Nutr Phys Act 9, 79.

8. Liu JH, Chu YH, Frongillo EA et al. (2012) Generation and acculturation status are associated with dietary intake and body weight in Mexican American adolescents. J Nutr 142, 298-305.

9. Champagne CM, Broyles ST, Moran LD et al. (2011) Dietary intakes associated with successful weight loss and maintenance during the Weight Loss Maintenance trial. J Am Diet Assoc 111, 1826-1835.

10. Dauchet L, Amouyel P, Hercberg S et al. (2006) Fruit and vegetable consumption and risk of coronary heart disease: a meta-analysis of cohort studies. J Nutr 136, 2588-2593.

11. Riboli E \& Norat T (2003) Epidemiologic evidence of the protective effect of fruit and vegetables on cancer risk. Am J Clin Nutr 78, 3 Suppl., 559S-569S.

12. Steinmetz KA \& Potter JD (1996) Vegetables, fruit, and cancer prevention: a review. J Am Diet Assoc 96, 1027-1039.

13. Van Duyn MA \& Pivonka E (2000) Overview of the health benefits of fruit and vegetable consumption for the dietetics professional: selected literature. J Am Diet Assoc 100, $1511-1521$.

14. World Cancer Research Fund/American Institute for Cancer Research (2007) Food, Nutrition, Physical Activity, and the Prevention of Cancer: A Global Perspective. Washington, DC: AICR.

15. Brock KE, Ke L, Gridley G et al. (2012) Fruit, vegetables, fibre and micronutrients and risk of US renal cell carcinoma. Br J Nutr 108, 1077-1085.

16. Guenther PM, Dodd KW, Reedy J et al. (2006) Most Americans eat much less than recommended amounts of fruits and vegetables. J Am Diet Assoc 106, 1371-1379.

17. Briefel RR \& Johnson CL (2004) Secular trends in dietary intake in the United States. Annu Rev Nutr 24, 401-431.

18. Casagrande SS, Wang Y, Anderson C et al. (2007) Have Americans increased their fruit and vegetable intake? The trends between 1988 and 2002. Am J Prev Med 32, 257-263. 
19. Fox MK \& Cole N (2008) Diet Quality of Americans by Food Stamp Participation Status: Data from the National Health and Nutrition Examination Survey, 1999-2004. Alexandria, VA: US Department of Agriculture, Food and Nutrition Service, Office of Research, Nutrition and Analysis.

20. Kamphuis CB, Giskes K, de Bruijn GJ et al. (2006) Environmental determinants of fruit and vegetable consumption among adults: a systematic review. BrJ Nutr 96, 620-635.

21. Government Accountability Office (2008) Food Stamp Program: Options for Delivering Financial Incentives to Participants for Purchasing Targeted Foods. Report no. GAO-08-415. Washington, DC: Government Printing Office.

22. Frazao E, Andrews M, Smallwood D et al. (2007) Food Spending Patterns of Low-Income Households: Will Increasing Purchasing Power Result in Healthier Food Choices? Economic Information Bulletin no. 29-4. Washington, DC: US Department of Agriculture, Economic Research Service.

23. Lin BH \& Guthrie JF (2007) How Do Low-Income Households Respond to Food Prices? Economic Information Bulletin no. 29-5. Washington, DC: US Department of Agriculture, Economic Research Service.

24. Ver Ploeg M, Breneman V, Farrigan T et al. (2009) Access to Affordable and Nutritious Food-Measuring and Understanding Food Deserts and Their Consequences: Report to Congress. Washington, DC: US Department of Agriculture, Economic Research Service.

25. Khan LK, Sobush K, Keener D et al.; Centers for Disease Control and Prevention (2009) Recommended community strategies and measurements to prevent obesity in the United States. MMWR Recomm Rep 58, 1-26.

26. Briggs S, Fisher A, Lott M et al. (2010) Real Food, Real Choice: Connecting SNAP Recipients with Farmers' Markets. Portland, OR: Community Food Security Coalition.

27. New York City Department of Health and Mental Hygiene (2012) Working with Farmers' Markets. http://www. nyc.gov/html/doh/html/cdp/cdp_pan_health_bucks.shtml (accessed July 2012).

28. Payne GH, Wethington H, Olsho L et al. (2013) Implementing a farmers' market incentive program: perspectives on the New York City Health Bucks Program. Prev Chronic Dis 10, 120285.

29. McCormack LA, Laska MN, Larson NI et al. (2010) Review of the nutritional implications of farmers' market and community gardens: a call for evaluation and research efforts. J Am Diet Assoc 110, 399-408.

30. Anliker J, Winne M \& Drake L (1992) An evaluation of the Connecticut farmers' market coupon program. J Nutr Educ 24, 185-191.

31. Blair D, Giesecke CC \& Sherman S (1991) A dietary, social and economic evaluation of the Philadelphia Urban Gardening project. J Nutr Educ 23, 161-167.
32. Olsho L, Baronberg S, Abel Y et al. (2012) Health Bucks Evaluation Tool Kit. http://centertrt.org/?p=intervention\&id=1109\&section=10 (accessed July 2012).

33. New York City Department of Health and Mental Hygiene (2012) Community Health Survey. http://www.nyc.gov/ html/doh/html/survey/survey.shtml (accessed July 2012).

34. Bertrand M, Duflo E \& Mullainathan S (2004) How much should we trust differences-in-differences estimates? QJ Econ 119, 249-275.

35. Freedman DA, Whiteside O, Brandt HM et al. (2012) Assessing readiness for establishing a farmers' market at a community health center. J Community Health 37, 80-88.

36. Cole K, McNees M, Kinney K et al. (2013) Increasing access to farmers markets for beneficiaries of nutrition assistance: evaluation of the farmers market access project. Prev Chronic Dis 10, 130121.

37. Evans A, Jennings R, Smiley A et al. (2012) Introduction of farm stands in low-income communities increases fruit and vegetable consumption among community residents. Health Place 18, 137-1143.

38. Baronberg S, Dunn L, Nonas C et al. (2013) The impact of New York City's Health Bucks Program on electronic benefit transfer spending at farmers markets, 2006-2009. Prev Chronic Dis 10, 130113.

39. Freedman DA, Mattison-Faye A, Kassandra A et al. (2014) Comparing farmers' market revenue trends before and after the implementation of a monetary incentive for recipients of food assistance. Prev Chronic Dis 11, 130347.

40. Young CR, Aquilante JL, Solomon S et al. (2013) Improving fruit and vegetable consumption among low-income customers at farmers markets: Philly Food Bucks, Philadelphia, Pennsylvania, 2011. Prev Chronic Dis 10, 120356.

41. Jilcott Pitts SB, Gustafson A, Wu Q et al. (2014) Farmers' market use is associated with fruit and vegetable consumption in diverse southern rural communities. Nutr J 13, 1 .

42. Winch R (2008) Nutrition Incentives at Farmers' markets: Bring Fresh, Healthy Local Foods within reach. http://www. farmlandinfo.org/documents/37781/ebt_matching_programs_ rachel_winch.pdf (accessed September 2009).

43. US Department of Agriculture, National Institute of Food and Agriculture (2014) Food Insecurity Nutrition Incentive (FINI) Grant Program: Request for Application. http://www.nifa. usda.gov/funding/rfas/fini.html (accessed February 2015).

44. Klerman JA, Bartlett S, Wilde P et al. (2014) The short-run impact of the Healthy Incentives Pilot Program on fruit and vegetable intake. Am J Agric Econ 96, 1372-1382.

45. Bartlett S, Klerman JA, Olsho L et al. (2014) Evaluation of the Healthy Incentives Pilot: Final Report. Alexandria, VA: Prepared by Abt Associates for the US Department of Agriculture, Food and Nutrition Service. 